\title{
Lightning strike evaluation on composite and biocomposite verticalaxis wind turbine blade using structural health monitoring approach
}

\begin{abstract}
ABSTRCT
Lightning damages to wind turbine blades increase as the size of wind turbine becomes larger. The damages are quite serious since it contributes to high cost of repairs and loss of electric power production. Since natural plant fibres receive attention nowadays due to low density and high specific strength, the usage of natural fibre to replace synthetic fibre in fabricating the turbine blade will promote a green renewable material. As the application of biocomposite for wind turbine blade has been explored, the effect of lightning strike damage has been required for further test investigation. This article explores the comparative results of performing lightning strike damage testing on composite (fibreglass) and biocomposite (flax fibre) wind turbine blades with protective metal mesh materials. The damage assessments were performed using visual non-destructive inspection methods and piezoelectric sensor as part of structural health monitoring. From the result, it is found that fibreglass blade experienced larger damage area compared to flax fibre blade based on the visual test conducted.
\end{abstract}

Keyword: Wind turbine; Biocomposite; Lightning strike damage; Lightning protection; Structural health monitoring 